\title{
Caracterização e análise sensorial de biscoitos de polvilho elaborados com diferentes níveis de farelo de mandioca
}

\author{
Characterization and sensory analysis of cassava starch biscuits made with different levels \\ of cassava bagasse
}

\author{
Janaína Pereira de Macedo Rodrigues ${ }^{\mathrm{I}}$ Márcio CaliariI ${ }^{\mathrm{II}}$ Eduardo Ramirez Asquieri ${ }^{\mathrm{III}}$
}

\section{RESUMO}

Objetivou-se com este trabalho avaliar as características químicas, cor, volume específico e aceitabilidade, de biscoitos elaborados com diferentes níveis de farelo de mandioca desidratado. Realizou-se previamente a desidratação do farelo de mandioca e, em seguida, elaboraram-se formulações de biscoitos com concentrações de farelo de mandioca de $0 \%$ (BP), 2\% (BF2), 4\% (BF4), 6\% (BF6) e 8\% (BF8), em substituição à fécula de mandioca. Os dados foram analisados por meio da análise de variância, teste de Tukey, em nível de 5\% de significância. O teor de fibra alimentar e os atributos de $\operatorname{cor}\left(L^{*}, a^{*} e b^{*}\right)$ dos biscoitos aumentaram significativamente com a adição do farelo de mandioca desidratado, o teor de fibra alimentar total variou de $5,47 \mathrm{~g}$ $100 \mathrm{~g}^{-1}$ a $11,40 \mathrm{~g} 100 \mathrm{~g}^{-1}$, o de proteínas variou de $6,66 \mathrm{~g} 100 \mathrm{~g}^{-1}$ a 7,26g $100 \mathrm{~g}^{-1}$. Em $100 \mathrm{~g}$ de biscoito de polvilho com $8 \%$ de farelo de mandioca, encontram-se atendidas 20\%, 32\%, 26\%, $38 \%, 79 \%, 16 \%$ e $20 \%$ da ingestão dietética de referência para o cálcio, cobre, fósforo, magnésio, manganês, potássio e zinco, respectivamente. $O$ volume específico dos biscoitos diminuiu com o aumento de farelo de mandioca. Os biscoitos apresentaram boa aceitabilidade para aparência, sabor $e$ textura. Conclui-se que biscoitos de polvilho elaborados com farelo de mandioca desidratado constituem um produto com bom potencial nutricional e de boa aceitabilidade.

Palavras-chave: farelo de mandioca, fibra alimentar, biscoito de polvilho, análise sensorial.

\section{ABSTRACT}

This study evaluated the chemically composition, color, specific volume and acceptability of biscuits made with cassava bagasse dehydrated. Held prior to the dehydration of

\begin{abstract}
cassava bagasse, then prepared themselves for producing biscuits with concentrations of cassava bagasse from $0 \%(B P)$, $2 \%$ (BF2), 4\% (BF4) 6\% (BF6) and 8\% (BF8), instead of cassava starch. Data were analyzed by analysis of variance, Tukey at 5\% level of significance. The dietary fiber content and attributes of color $\left(L^{*}, a^{*} b^{*}\right)$ the biscuits increased with the addition of cassava bagasse dehydrated, the dietary fiber content

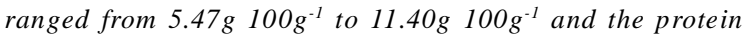

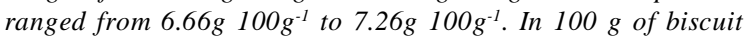
with $8 \%$ of cassava bagasse dehydrated are met $20 \%, 32 \%$, $26 \%, 38 \%, 79 \%, 16 \%$ and $20 \%$ of dietary reference intakes for calcium, copper, phosphorus, magnesium, manganese, potassium and zinc, respectively. The specific volume of biscuits decreased with the increase of cassava bagasse. The biscuits were good acceptance for appearance, flavor and texture. It is concluded that cassava biscuits made with cassava meal dehydrated form a product with good nutritional potential and good acceptability.
\end{abstract}

Key words: cassava bagasse, dietary fiber, cassava starch biscuits, sensory analysis.

\section{INTRODUÇÃO}

Os subprodutos da mandioca são partes constituintes da própria planta, gerados em função do processo tecnológico adotado. Tanto a qualidade como a quantidade dos subprodutos variam bastante, em função de uma série de fatores, tais como cultivar, idade da planta, tempo após a colheita, tipo e regulagem do equipamento industrial. Um subproduto importante no

'Programa de Pós-graduação em Ciência e Tecnologia de Alimentos, Universidade Federal de Goiás (UFG), 74917-040, Goiânia, GO, Brasil. E-mail: janainapm@gmail.com. Autor para correspondência.

"Departamento de Engenharia de Alimentos, UFG, Goiânia, GO, Brasil.

IIIDepartamento de Análises Clínicas Toxicológicas e Bromatológicas, UFG, Goiânia, GO, Brasil. 
processo de extração de fécula de mandioca é o farelo ou bagaço, caracterizado como material fibroso da raiz, contendo parte da fécula que não foi possível extrair no processamento. A elevada quantidade de farelo gerado e a sua umidade, em torno de $85 \%$, fazem com que esse material se apresente como um problema durante a safra, devido às dificuldades de transporte e armazenamento. O despejo indevido dos subprodutos de mandioca, além de agredir o meio ambiente, constitui desperdício de rendimentos para a indústria (LEONEL, 2001).

A indústria processadora de mandioca, ainda, não atentou que um aproveitamento eficiente de seus resíduos é um fator determinante para a sua diferenciação num futuro bastante próximo. Muitas possibilidades de uso do farelo de mandioca já foram pesquisadas e não se pode dizer que exista uma solução única, e sim usos potenciais de acordo com a situação de mercado e da fecularia. $\mathrm{O}$ farelo de mandioca possui quantidades significativas de carboidratos, amido e alta concentração de fibras alimentares, principalmente fibras insolúveis (CEREDA, 2001; LEONEL, 2001).

Dentre as possibilidades de uso estudadas e algumas já testadas em escala piloto, destacam-se o uso do farelo, juntamente com complementos protéicos, na formulação de rações para bovinos, uso do farelo como matéria prima para produção de etanol, produção de carvão, enchimento para comprimidos, embalagens biodegradáveis e o farelo como base para produtos dietéticos ricos em fibras. Nesse contexto, o farelo aparece como um resíduo que apresenta grande potencialidade de vir a se tornar um co-produto das indústrias extratoras de amido de mandioca (LEONEL et al., 1998; LEONEL et al., 1999; LEONEL, 2001).

O biscoito de polvilho é um produto crocante. Essa característica é típica de produtos que se encontram no estado vítreo, caracterizado por apresentar baixa mobilidade molecular. O biscoito, ao passar pelo processo de assamento e, devido à rápida remoção de água e, de acordo com o seu teor de umidade final, ao término do processo, encontrar-seá no estado vítreo. Dependendo das condições de armazenamento, ele pode sofrer alteração pela sorção de umidade e, assim, ocorrer uma maior mobilidade das moléculas, passando do estado vítreo para o gomoso, fenômeno conhecido como transição vítrea (RIBEIRO, 2006).

Objetivou-se com este trabalho avaliar as características físicas, químicas, teor de fibras, proteínas e a aceitabilidade de biscoitos de polvilho, elaborados com diferentes níveis de substituição de fécula de mandioca por farelo de mandioca desidratado.

\section{MATERIAL E MÉTODOS}

As amostras de fécula e farelo de mandioca foram doadas pela Fecularia Bela Vista (FEBELA), localizada no município de Bela Vista de Goiás, Goiás (GO). A fécula de mandioca foi embalada em sacos de polietileno de baixa densidade e armazenada a $-18^{\circ} \mathrm{C}$ até o processamento dos biscoitos. $\mathrm{O}$ farelo de mandioca foi desidratado em estufa com circulação de ar forçado a $60^{\circ} \mathrm{C}$ por 26 horas. $\mathrm{O}$ farelo depois de desidratado foi moído em moinho de facas tipo willey até a obtenção de farinha fina (60 mesh), a seguir, foi embalado em sacos de polietileno e armazenado a $-18^{\circ} \mathrm{C}$, até o processamento dos biscoitos.

Para a elaboração dos biscoitos, utilizou-se de uma formulação de biscoito padrão (BP) e quatro formulações com diferentes substituições de fécula por farelo de mandioca desidratado (2\%, $4 \%, 6 \%$ e $8 \%)$, resultando nos biscoitos $\mathrm{BF} 2, \mathrm{BF} 4, \mathrm{BF} 6$ e BF8. Os biscoitos foram preparados no Laboratório de Técnica Dietética da Faculdade de Nutrição da Universidade Federal de Goiás (UFG). Em todos os tratamentos, as quantidades de farelo de mandioca desidratado variaram e os demais ingredientes permaneceram constantes (Tabela 1).

Em uma batedeira elétrica planetária doméstica Arno, foram misturados a fécula de mandioca, o farelo de mandioca desidratado e o sal, em velocidade baixa, por um minuto. A seguir, foi realizado o escaldamento desse material, adicionando-se uma mistura fervente $\left(97^{\circ} \mathrm{C}\right)$ com a água e o óleo, e misturando por mais dois minutos em velocidade baixa. Sem desligar a batedeira, adicionaram-se os ovos,

Tabela 1 - Formulações do biscoito padrão e dos biscoitos com farelo de mandioca desidratado.

\begin{tabular}{llllll}
\hline Ingredientes & $\mathrm{BP}$ & $\mathrm{BF} 2$ & $\mathrm{BF} 4$ & $\mathrm{BF6}$ & $\mathrm{BF8}$ \\
\hline Fécula de mandioca $(\mathrm{g})$ & 100,0 & 98,0 & 96,0 & 94,0 & 92,0 \\
Farelo de mandioca $(\mathrm{g})$ & - & 2,0 & 4,0 & 6,0 & 8,0 \\
Ovos $(\mathrm{g})$ & 60,0 & 60,0 & 60,0 & 60,0 & 60,0 \\
Água $(\mathrm{mL})$ & 50,0 & 50,0 & 50,0 & 50,0 & 50,0 \\
Óleo $(\mathrm{g})$ & 15,0 & 15,0 & 15,0 & 15,0 & 15,0 \\
Sal $(\mathrm{g})$ & 3,0 & 3,0 & 3,0 & 3,0 & 3,0 \\
\hline
\end{tabular}

Ciência Rural, v.41, n.12, dez, 2011. 
misturando por mais dois minutos, em velocidade média. Para melhor homogeneização, a massa foi mantida sob batimento por mais três minutos em velocidade alta. A massa foi usada para moldar os biscoitos, com aproximadamente $7 \mathrm{~cm}$ de comprimento e $12 \mathrm{~mm}$ de diâmetro, distribuídos uniformemente em assadeira com o auxílio de um bico de confeitar. Os biscoitos foram assados em um forno elétrico da marca Layr, a temperatura de $200^{\circ} \mathrm{C}$, por aproximadamente 25 minutos, sendo, posteriormente, resfriados até atingirem a temperatura ambiente. Os biscoitos foram embalados em sacos de polietileno de baixa densidade até a realização da avaliação sensorial. Amostras, de cada tratamento, foram congeladas a $-18^{\circ} \mathrm{C}$ até a realização das análises físicas e químicas.

As amostras foram submetidas a análises de umidade (INSTITUTO ADOLFO LUTZ, 2005); as cinzas e as proteínas foram determinadas segundo metodologia da AOAC (1990); os lipídios totais, segundo BLIGH \& DYER (1959). Para a determinação do amido, foi utilizada a metodologia de hidrólise ácida (CEREDA et al., 2004) e sua determinação realizada pela dosagem de açúcares redutores, método 3,5 dinitrosalicílico (MILLER, 1959), multiplicando seu resultado pelo fator 0,9 , que transforma açúcares redutores em amido. A fibra alimentar total, solúvel e insolúvel, foi determinada conforme técnica enzímicagravimétrica descrita por PROSKY et al. (1988). Aacidez titulável e o pH também foram determinados segundo método descrito pelo INSTITUTO ADOLFO LUTZ (2005). O fator ácido foi determinado, segundo metodologia descrita por MARCONI et al. (2007). Cálcio, cobre, fósforo, magnésio, manganês, potássio, zinco e enxofre foram analisados, conforme método da AOAC (1990). Todas as análises de caracterização química foram determinadas com quinze repetições; as análises de fibra foram realizadas em quadruplicata.

Os parâmetros instrumentais de cor $\left(\mathrm{L}, a^{*} \mathrm{e}\right.$ $\left.b^{*}\right)$ dos biscoitos foram determinados no Colorímetro Hunter Lab, modelo Color Quest II, no Laboratório de Análises Físico-Químicas de Alimentos da Escola de Engenharia de Alimentos (EA) da UFG, Goiânia, GO, com quinze repetições (HUNTERLAB, 1998). O volume específico foi determinado, em quinze repetições, de acordo com a metodologia descrita por SILVA et al. (1998), pelo método de deslocamento de sementes de painço.

Para a análise sensorial, cada biscoito foi avaliado por cinquenta provadores não treinados, de forma monádica. $\mathrm{O}$ método utilizado foi o teste de aceitabilidade, no qual se avaliou os atributos aparência, sabor e textura, por meio da escala hedônica de nove pontos, que variou de 1 (desgostei extremamente) a 9 (gostei extremamente) (STONE \& SIDEL, 2004). Os dados obtidos foram submetidos à análise de variância (ANOVA) e teste de Tukey para comparação de médias, ao nível de significância de $5 \%$. Os cálculos estatísticos foram efetuados com auxílio do programa Excel-versão 2007 e do programa Statistica - Stat Soft Inc., versão 7, 2004, Tulsa, EUA.

\section{RESULTADOS E DISCUSSÃO}

Os resultados da caracterização química estão apresentados na tabela 2. Em relação à umidade, os biscoitos $\mathrm{BP}$ e BF4, e BF2 e BF8 não diferiram $(\mathrm{P}>0,05)$ entre si; porém, o biscoito BF6 diferiu $(\mathrm{P} \leq 0,05)$ dos demais, isso significa dizer que o conteúdo de farelo de mandioca adicionado não afetou a sua umidade. Umidades variando entre 1,54 e $11,53 \mathrm{~g} 100 \mathrm{~g}^{-1}$ foram obtidas por SILVA et al. (1998) estudando biscoitos de amido de mandioca obtidos por fermentação natural.

Tabela 2 - Caracterização química dos biscoitos elaborados com diferentes níveis de substituição de fécula de mandioca por farelo de mandioca desidratado com as médias, os desvios-padrão e coeficientes de variação.

\begin{tabular}{lccccc}
\hline Componente $^{1}\left({\left.\mathrm{~g} 100 \mathrm{~g}^{-1}\right)}^{1}\right.$ & BP & BF2 & BF4 & BF6 & BF8 \\
\hline Umidade & $6,89 \pm 0,16^{\mathrm{a}}$ & $5,77 \pm 0,15^{\mathrm{c}}$ & $6,83 \pm 0,19^{\mathrm{a}}$ & $6,50 \pm 0,09^{\mathrm{b}}$ & $5,74 \pm 0,04^{\mathrm{c}}$ \\
Proteínas & $6,90 \pm 0,09^{\mathrm{b}}$ & $6,94 \pm 0,04^{\mathrm{b}}$ & $7,26 \pm 0,12^{\mathrm{a}}$ & $6,76 \pm 0,10^{\mathrm{c}}$ & $6,66 \pm 0,07^{\mathrm{c}}$ \\
Lipídeos totais $_{\text {Cinzas }}^{15,07 \pm 1,10^{\mathrm{a}}}$ & $15,57 \pm 1,14^{\mathrm{a}}$ & $15,61 \pm 0,71^{\mathrm{a}}$ & $16,27 \pm 0,71^{\mathrm{a}}$ & $15,96 \pm 1,24^{\mathrm{a}}$ \\
Fibra alimentar total & $2,91 \pm 0,03^{\mathrm{b}}$ & $2,94 \pm 0,09^{\mathrm{ab}}$ & $3,01 \pm 0,05^{\mathrm{a}}$ & $2,97 \pm 0,07^{\mathrm{ab}}$ & $2,99 \pm 0,07^{\mathrm{ab}}$ \\
Amido $^{2}$ & $5,47 \pm 0,23^{\mathrm{e}}$ & $7,40 \pm 0,10^{\mathrm{d}}$ & $8,53 \pm 0,23^{\mathrm{c}}$ & $10,23 \pm 0,23^{\mathrm{b}}$ & $11,40 \pm 0,26^{\mathrm{a}}$ \\
Acidez $^{2}$ & $75,75 \pm 0,84^{\mathrm{d}}$ & $76,27 \pm 1,89^{\mathrm{cd}}$ & $77,40 \pm 0,83^{\mathrm{bc}}$ & $78,28 \pm 0,81^{\mathrm{b}}$ & $80,68 \pm 0,92^{\mathrm{a}}$ \\
pH $_{\text {Fator ácido }}^{3}$ & $2,03 \pm 0,00^{\mathrm{a}}$ & $2,03 \pm 0,00^{\mathrm{a}}$ & $2,03 \pm 0,00^{\mathrm{a}}$ & $2,03 \pm 0,00^{\mathrm{a}}$ & $2,03 \pm 0,00^{\mathrm{a}}$ \\
\hline
\end{tabular}

${ }^{1}$ As médias, exceto umidade, foram calculadas em base seca. Em uma mesma linha, médias com letras iguais não apresentam diferenças significativas pelo teste de Tukey a $5 \%$ de probabilidade.

${ }^{2} \mathrm{~mL}$ de $\mathrm{NaOH} 0,1 \mathrm{~N} / 100 \mathrm{~g}$ amostra.

${ }^{3} \mathrm{~mL}$ de ácido clorídrico. 
Com relação ao teor protéico dos biscoitos, houve diferença significativa $(\mathrm{P} \leq 0,05)$ entre os biscoitos $\mathrm{BP}, \mathrm{BF} 4$ e BF6; e não houve diferença significativa $(\mathrm{P}>0,05)$ entre os biscoitos BPe BF2 e BF6 e BF8. Além disso, o teor de proteínas para os biscoitos em questão variou de 6,76 a $7,26 \mathrm{~g} 100 \mathrm{~g}^{-1}$. Resultados diferentes foram relatados por APLEVICZ \& DEMIATE (2007),

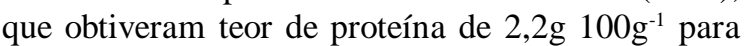
biscoitos elaborados com polvilho azedo e com polvilho doce. Essa diferença pode estar relacionada com as matérias-primas utilizadas na elaboração dos biscoitos e/ou com as quantidades dos ingredientes utilizados na formulação dos biscoitos. Para o teor de lipídios, não houve diferença significativa $(\mathrm{P}>0,05)$ entre os biscoitos analisados, que apresentaram médias de

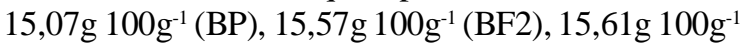

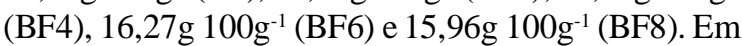
relação ao teor de cinzas, não houve diferença significativa $(\mathrm{P}>0,05)$ entre os biscoitos $\mathrm{BF} 2$, BF6 e BF8. O resultado de teor de cinzas, $1,72 \mathrm{~g} 100 \mathrm{~g}^{-1}$, obtido por RIBEIRO (2006), no trabalho que avaliou o efeito da formulação nas propriedades físico-químicas do biscoito de polvilho, é 72,09\% maior que a média dos teores de cinzas obtidos neste estudo.

Houve um aumento gradual do teor de fibras dos biscoitos com a elevação do incremento do farelo de mandioca desidratado. Todos os biscoitos formulados diferiram entre si $(\mathrm{P} \leq 0,05)$. Comparando-se o teor de fibra alimentar total entre as amostras BP e BF8, pode-se observar que o biscoito BF8 possui cerca de $108,41 \%$ mais de fibra em sua composição que o biscoito BP. Sendo assim, o biscoito BP pode ser considerado como um alimento fonte de fibra alimentar; e o biscoito BF8, como um alimento com alto teor de fibra. Segundo a Portaria no 27, de 13 de janeiro de 1998, um alimento sólido com, no mínimo, de $3{\mathrm{~g} 100 \mathrm{~g}^{-1}}^{-1}$ de fibras já pode ser classificado como fonte de fibra alimentar (BRASIL, 1998). A Ingestão Dietética de Referência (Dietary Reference Intakes) (DRI) de fibra alimentar para adultos é de $25-38 \mathrm{~g} \mathrm{dia}^{-1}$, sendo que homens devem ingerir maior quantidade de fibra que as mulheres, $38 \mathrm{~g} \mathrm{dia}^{-1}$ e $25-26 \mathrm{~g} \mathrm{dia}^{-1}$, respectivamente (WHITNEY \& ROLFES, 2008; COLLI et al.; 2005; MAHAN \& ESCOTT-STUMP, 2005). Comparando-se a DRI às quantidades de fibras alimentares presentes em 100 $\mathrm{g}$ do biscoito BF8, encontram-se atendidas em $30 \%$ da DRI para homens e $45,60 \%$ da DRI para mulheres.

De acordo com o incremento de farelo de mandioca desidratado na formulação dos biscoitos, $\mathrm{o}$ teor de amido também aumentou. O biscoito BP

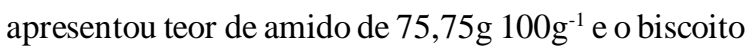
BF8 de 80,68g 100 g $\mathrm{g}^{-1}$; assim, o biscoito BF8 tem teor de amido $6,51 \%$ maior que o biscoito BP. Num estudo sobre caracterização química de polvilhos doces e de produtos derivados da mandioca, no Estado de São Paulo, PEREIRA \& LEONEL (2009) obtiveram teor de

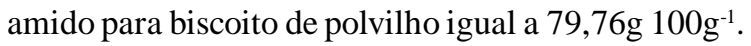
Este resultado está de acordo com os resultados obtidos neste estudo.

Quanto aos resultados de acidez titulável e $\mathrm{pH}$, pode-se observar que não houve diferença significativa $(\mathrm{P}>0,05)$ entre as amostras de biscoitos analisadas. Todos os biscoitos analisados apresentaram o mesmo valor para acidez titulável $(2,03 \mathrm{~mL}$ de $\mathrm{NaOH}$ $\left.0,1 \mathrm{~N} 100 \mathrm{~g}^{-1}\right)$. Os valores de $\mathrm{pH}$ obtidos para os biscoitos $\mathrm{BP}, \mathrm{BF} 2, \mathrm{BF} 4, \mathrm{BF} 6$ e BF8, foram iguais a $6,44,6,44,6,43$, 6,39 e 6,40, respectivamente, não havendo diferença significativa $(\mathrm{P}>0,05)$ entre eles.

As substituições de 2 a $8 \%$ de farelo de mandioca nas formulações dos biscoitos não interferiram de forma significativa nos resultados de acidez e pH; sendo que os demais componentes das formulações foram mantidos constantes. $\mathrm{O}$ fator ácido consiste em uma avaliação que expressa o grau de pureza do grânulo de amido (MARCONI et al., 2007). As amostras de biscoito BP, BF4, BF6 e BF8 diferiram entre si $(\mathrm{P} \leq 0,05)$; porém, entre as amostras $\mathrm{BP}$ e $\mathrm{BF} 2$, não houve diferença significativa $(\mathrm{P}>0,05)$. A pureza dos grânulos de amido do farelo de mandioca é inferior à fécula; provavelmente, essa diferença interferiu no fator ácido das formulações.

O conteúdo de minerais variou de 200,00 a

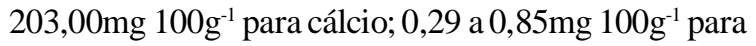
cobre; 30,00 a $60,00 \mathrm{mg}^{100 \mathrm{~g}^{-1}}$ para enxofre; $183,00 \mathrm{a}$

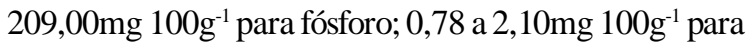
manganês; 780,00 a 793,33mg $100 \mathrm{~g}^{-1}$ para o potássio;

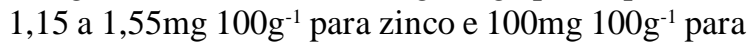
magnésio, entre os tratamentos. Os valores de minerais encontrados para o biscoito BF8 foram: $\mathrm{Ca}(201,00 \mathrm{mg}$

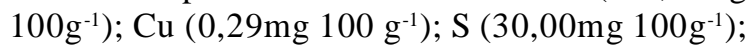

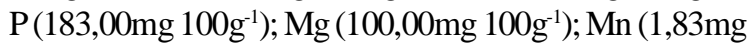
$\left.100 \mathrm{~g}^{-1}\right) ; \mathrm{K}\left(780,00 \mathrm{mg}^{100 \mathrm{~g}^{-1}}\right)$ eZn $\left(1,41 \mathrm{mg}^{100 \mathrm{~g}^{-1}}\right)$. Num estudo sobre a qualidade de biscoitos elaborados com farelo de arroz extrusado em substituição à farinha de trigo e fécula de mandioca, os teores de minerais obtidos

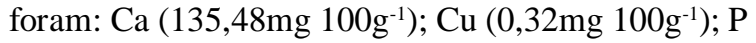

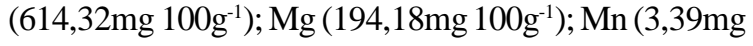
$\left.100 \mathrm{~g}^{-1}\right)$; K $\left(503,20 \mathrm{mg}^{100 \mathrm{~g}^{-1}}\right)$ e Zn $\left(1,88 \mathrm{mg}^{\left.100 \mathrm{~g}^{-1}\right)}\right.$ (LACERDA et al., 2009). Comparando-se os conteúdos de minerais do biscoito BF8 com os resultados encontrados por LACERDA et al. (2009), pode-se afirmar que os minerais fósforo, magnésio, manganês, zinco e cobre, desse biscoito, são menores e representaram $29,79 \%, 51,50 \%, 53,98 \%, 75,00 \%$ e $90,63 \%$, respectivamente, dos encontrados naquele estudo. Para os conteúdos de cálcio e potássio, os 
valores do biscoito BF8 são 49,84\% e 55,01\%, respectivamente, maiores que os encontrados nos biscoitos elaborados com farelo de arroz extrusado em substituição à farinha de trigo e fécula de mandioca. Comparando-se a DRI às quantidades de minerais presentes em 100g do biscoito BF8, encontram-se atendidas $20 \%$ da DRI para o cálcio, $32 \%$ para o cobre, $26 \%$ para o fósforo, $38 \%$ para magnésio, $79 \%$ para o manganês e $20 \%$ para o zinco.

A luminosidade $\mathrm{L}^{*}$ tendeu à diminuição do valor, ou seja, ao escurecimento dos biscoitos com aumento de substituição da fécula de mandioca pelo farelo de mandioca desidratado. Todas as amostras de biscoito de polvilho apresentaram diferença significativa entre si $(\mathrm{P} \leq 0,05)$, sendo que a amostra BF8 apresentou menor valor de luminosidade $L^{*}(46,51)$ e a amostra BP apresentou maior luminosidade $\mathrm{L}^{*}$ $(66,52)$. O biscoito BF8 apresentou-se $143 \%$ mais escuro que o biscoito BP. A substituição da fécula de mandioca por farelo de mandioca desidratado possibilitou um incremento nas colorações amarelo e vermelha dos tratamentos. Assim sendo, é possível dizer que a cor adquirida pelos biscoitos pode ser devido à reação de Maillard, principalmente em materiais que apresentam teores relativamente altos de carboidrato, à quantidade de farelo adicionado, ao tempo e temperatura de assamento deles (GUTKOSKI et al., 2007).

O volume específicoé de grande importância na determinação da qualidade, porque geralmente é influenciado pela qualidade dos ingredientes usados na formulação (EL-DASH et al., 1982). Segundo CAMARGO et al. (1988), o biscoito de polvilho apresenta, no seu interior, uma matriz de amido gelatinizado que é responsável pela sua expansão e textura. Durante o forneamento, os grânulos da superfície são desidratados e aqueles do interior gelatinizados, provocando a expansão do biscoito. A propriedade de expansão é uma das características mais relevantes do produto e também a mais interessante para os fabricantes de biscoito (RIVERA, 1997). Biscoitos com expansão muito alta ou muito baixa causam problemas na indústria, resultando em produtos com tamanho pequeno ou peso muito elevado (FERREIRA et al., 2009). Observou-se uma tendência de redução nos volumes específicos à medida que aumentaram as adições de farelo de mandioca. Para o biscoito BP, o volume específico foi de $3,35 \mathrm{~mL} \mathrm{~g}^{-1}$, já para o biscoito BF8 o volume específico foi igual a $2,22 \mathrm{~mL} \mathrm{~g}^{-1}$, tendo uma redução no volume específico de $33,73 \%$. Os biscoitos elaborados com polvilho azedo tendem a apresentar maior volume específico que os biscoitos elaborados com fécula de mandioca. Essa informação pode ser constatada no estudo realizado por DIAS et al. (2007), em que o volume específico obtido para biscoitos formulados com polvilho azedo variou entre $3,67 \mathrm{~mL} \mathrm{~g}^{-1}$ e $15,04 \mathrm{~mL} \mathrm{~g}^{-1}$.

Os resultados obtidos no teste de aceitabilidade estão apresentados na tabela 3 . As amostras de biscoito $\mathrm{BP}, \mathrm{BF} 2, \mathrm{BF} 6$ e BF8 não apresentaram diferença significativa $(P>0,05)$ em relação à aparência; sendo que a amostra BF4 apresentou o maior valor para esse quesito, 7,62, não diferindo estatisticamente $(\mathrm{P}>0,05)$ do biscoito BF6. Quanto ao sabor, as amostras menos aceitas foram as dos biscoitos BP e BF8. Não houve diferença significativa $(\mathrm{P}>0,05)$ entre as amostras de biscoitos BF2, BF4, BF6 e BF8, em relação ao sabor. Também não houve diferença significativa $(\mathrm{P}>0,05)$ em relação aos escores atribuídos à textura dos biscoitos. Os escores obtidos para os atributos aparência, sabor e textura variaram entre 6 (gostei ligeiramente) e 7 (gostei moderadamente), para todos os biscoitos. Biscoitos de polvilho, elaborados com $8,5 \%$ de farelo de trigo + $1,5 \%$ de polidextrose foram menos aceitos que biscoitos elaborados com $1,5 \%$ de farelo de trigo $+8,5 \%$ de polidextrose (MONTENEGRO et al., 2008).

\section{CONCLUSÃO}

$\mathrm{O}$ incremento de farelo de mandioca nos biscoitos influenciou nos atributos de cor $\left(\mathrm{L}^{*}, \mathrm{a}^{*} \mathrm{e}\right.$ $\mathrm{b}^{*}$ ), no volume específico e no teor de fibra alimentar, sendo que os atributos de cor e o teor de fibra aumentaram, e o volume específico diminuiu, à medida que foi adicionado mais farelo de mandioca na formulação. Todos os biscoitos elaborados com farelo de mandioca podem ser considerados como alimentos ricos em fibra alimentar. Quanto à aceitação, os biscoitos $\mathrm{BF} 4, \mathrm{BF} 2$ e BF4 foram os mais aceitos em relação à aparência, sabor e textura, respectivamente. Em relação aos minerais, pode-se afirmar que a substituição de fécula por farelo de mandioca não alterou significativamente os teores de potássio, cálcio e

Tabela 3 - Médias dos escores de aceitação para aparência, sabor e textura dos biscoitos formulados.

\begin{tabular}{lccc}
\hline Tipo de biscoito & Aparência $^{1}$ & Sabor $^{1}$ & Textura $^{1}$ \\
\hline BP & $6,76 \pm 1,38^{\mathrm{b}}$ & $6,78 \pm 1,12^{\mathrm{b}}$ & $6,73 \pm 1,09^{\mathrm{a}}$ \\
BF2 & $6,60 \pm 1,28^{\mathrm{b}}$ & $7,48 \pm 0,93^{\mathrm{a}}$ & $6,70 \pm 1,36^{\mathrm{a}}$ \\
BF4 & $7,62 \pm 0,88^{\mathrm{a}}$ & $7,42 \pm 0,95^{\mathrm{a}}$ & $7,42 \pm 1,43^{\mathrm{a}}$ \\
BF6 & $7,00 \pm 1,12^{\mathrm{ab}}$ & $7,42 \pm 0,88^{\mathrm{a}}$ & $6,68 \pm 1,54^{\mathrm{a}}$ \\
BF8 & $6,80 \pm 1,05^{\mathrm{b}}$ & $6,98 \pm 1,46^{\mathrm{ab}}$ & $6,80 \pm 1,43^{\mathrm{a}}$ \\
\hline
\end{tabular}

${ }^{1}$ Letras iguais na mesma coluna não diferem a $5 \%$ de probabilidade de erro pelo teste Tukey. 
magnésio. Entretanto, alterou significativamente os teores de fósforo, enxofre, cobre, manganês e zinco, comparando-se o biscoito padrão às demais formulações. O consumo de biscoitos elaborados com farelo de mandioca pode garantir ao consumidor um alimento de qualidade sensorial, nutricional e funcional.

\section{AGRADECIMENTOS}

À Universidade Federal de Goiás, à Fundação de Amparo a Pesquisa do Estado de Goiás (FAPEG) e à Fecularia Bela Vista.

\section{REFERÊNCIAS}

APLEVICZ, K.S.; DEMIATE, I.M. Caracterização de amidos de mandioca nativos e modificados e utilização em produtos panificados. Ciência e Tecnologia de Alimentos, Campinas, v.27, n.3, p.478-484, 2007. Disponível em: <http:// www.scielo.br/pdf/cta/v27n3/ a09v27n3.pdf>. Acesso em: 22 dez. 2009. doi: 10.1590/S0101-20612007000300009.

ASSOCIATION OFFICIAL ANALYTICAL CHEMISTS (AOAC). Official methods of analysis. 10.ed. Washington: AOAC, 1990. 1115p.

BLIGH, E.G.; DYER, W.J. A rapid method of total lipid extraction and purification. Canadian Journal of Biochemistry and Physiology, Toronto, v.37, n.8, p.911-917, 1959. Disponível e m: $<$ http://rparticle.web-p.cisti.nrc.ca/rparticle/ AbstractTemplateServlet?calyLang=eng\&journal $=$ cjpp\&volume $=37 \&$ year $=1959 \&$ issue $=8 \& m s n o=y 59-099>$. Acesso em: 20 dez. 2009 .

BRASIL. Agência Nacional de Vigilância Sanitária. Portaria n.27, de 13 de janeiro de 1998. Aprova o regulamento técnico sobre a informação nutricional complementar. Brasília, DF: ANVISA, 1998. Disponível em: <http://e-legis.bvs/leisref/ public/showAct.php?id=97\#>. Acesso em: 27 nov. 2009.

CAMARGO, C. et al. Functional properties of sour cassava (Manihot utilissima). Starch: polvilho azedo. Journal of the Science of Food and Agriculture, New Jersey, v.45, n.3, p.273289, 1988. Disponível em: <http://onlinelibrary.wiley.com/doi/ 10.1002/jsfa.2740450311/ abstract>. Acesso em: 8 dez. 2010. doi: $10.1002 /$ jsfa. 2740450311 .

CEREDA, M.P. Caracterização dos subprodutos da industrialização da mandioca. In: FUNDAÇÃO CARGILL. Manejo, uso e tratamento de subprodutos da industrialização. São Paulo: Fundação Cargill, 2001. V.4, cap.1, p.13-37. (Série Culturas de Tuberosas Amiláceas Latino Americanas). Disponível em: <http:/ /www.abam.com.br/livroscargil/>. Acesso em: 25 abr. 2008.

CEREDA, M.P. et al. Metodologia de determinação de amido digestão ácida em microondas. ABAM: Associação Brasileira dos Produtores de Amido de Mandioca, 2004. Ano II, n.8. Disponível em: <http://www.abam.com.br/revista/revista8/ metodologia.php>. Acesso em: 26 nov. 2009.

COLLI, C. et al. Alimentos funcionais. In: CUPPARI, L. Guia de nutrição: nutrição clínica no adulto. 2.ed. Barueri: Manole, 2005. Cap.5, p.71-87.

DIAS, A.R.G. et al. Oxidação dos amidos de mandioca e de milho comum fermentados: desenvolvimento da propriedade de expansão. Ciência e Tecnologia de Alimentos, Campinas, v.27, n.4, p.794-799, 2007. Disponível em: <http:// www.scielo.br/pdf /cta/v27n4/19.pdf>. Acesso em: 12 jan. 2010. doi: 10.1590/S0101-20612007000400019.

EL-DASH, A.A. et al. Fundamentos da tecnologia de panificação. São Paulo: Secretária da Indústria, Comércio, Ciência e Tecnologia, 1982. 349p. (Série Tecnologia Agroindustrial, 6).

FERREIRA, S.M.R. et al. Cookies sem glúten a partir da farinha de sorgo. Archivos Latinoamericanos de Nutricion, Caracas, v.59, n.4, p.433-440, 2009. Disponível em: <http:// www.alanrevista.org/ediciones/2009-4/pdf/art12.pdf>. Acesso em: 05 abr. 2010.

GUTKOSKI, L.C. et al. Biscoitos de aveia tipo cookie enriquecidos com concentrado de $\beta$-glicanas. Brazilian Journal of Food and Technology, Campinas, v.10, n.2, p.104-110, 2007. Disponível em: <http://www.ital.sp.gov.br/bj/artigos/html/busca/ PDF/v10n2279a.pdf $>$. Acesso em: 18 mar. 2010.

HUNTERLAB. User's manual with universal software versions 3.5. Reston, 1998. Paginação irregular.

INSTITUTO ADOLFO LUTZ. Normas analíticas do Instituto Adolfo Lutz: métodos físico-químicos para análise de alimentos. 4.ed. Brasília: Ministério da Saúde, Agência Nacional de Vigilância Sanitária, 2005. 1018p.

LACERDA, D.B.C.L. et al. Qualidade de biscoitos elaborados com farelo de arroz extrusado em substituição à farinha de trigo e fécula de mandioca. Archivos Latinoamericanos de Nutricion, Caracas, v.59, n.2, p.199-205, 2009. Disponível em: <http:// www.alanrevista.org/ediciones/2009-2/pdf/art13.pdf>. Acesso em: 16 abr. 2010.

LEONEL, M. et al. Cassava bagasse as dietary product. Tropical Science, New York, v.38, p.224-228, 1998. Disponível em: $<$ http://onlinelibrary. wiley.com/journal/10.1002/(ISSN)15569179>. Acesso em: 25 abr. 2009.

LEONEL, M. et al. Aproveitamento do resíduo da produção de etanol a partir de farelo de mandioca, como fonte de fibras dietéticas. Ciência e Tecnologia de Alimentos, Campinas, v.19, n.2, p.241-245, 1999. Disponível em: <http:// www.scielo.br/scielo.php? script $=$ sci_arttext\&pid $=$ S0 101 $20611999000200016 \& \operatorname{lng}=$ pt\&nrm $=$ iso $>$. Acesso em: 12 out. 2009. doi: 10.1590/S0101-20611999000200016.

LEONEL, M. O farelo, subproduto da extração da fécula de mandioca. In: FUNDAÇÃO CARGILL. Manejo, uso e tratamento de subprodutos da industrialização da mandioca. São Paulo: Fundação Cargill, 2001. V.4, cap.15, p.211-217. (Série Culturas de Tuberosas Amiláceas Latino Americanas). Disponível em: <http://www.abam.com.br/ fund_cargil.php>. Acesso em: 25 abr. 2009.

MAHAN, L.K.; ESCOTT-STUMP, S. Krause: alimentos, nutrição e dietoterapia. 11.ed. São Paulo: Rocca, 2005. 1242p.

MARCONI, M.J.A. et al. Propriedades químicas e tecnológicas do amido de mandioca e do polvilho azedo. Florianópolis: UFSC, 2007. $101 \mathrm{p}$.

MILLER, G.L. Use of dinitrosalicylic acid reagent for determination of reducing sugar. Analytical Chemistry, 
Washington, v.31, n.3, p.426-428, 1959. Disponível em: <http:/ /pubs.acs.org/doi/abs/10.1021/ac60147a030>. Acesso em: 10 nov. 2009.

MONTENEGRO, F.M. et al. Biscoitos de polvilho azedo enriquecidos com fibras solúveis e insolúveis. Ciência e Tecnologia de Alimentos, Campinas, v.28 (supl.), p.184191, 2008. Disponível em: <http://www.scielo.br/pdf/cta/v28s0/ 29.pdf>. Acesso em: 12 abr. 2010. doi: 10.1590/S010120612008000500029.

PEREIRA, B.B.; LEONEL, M. Caracterização química de polvilhos doces e produtos derivados da mandioca. In: CONGRESSO BRASILEIRO DE MANDIOCA, 13., 2009, Botucatu. Anais... Botucatu: CERAT/UNESP, 2009. p.1216.

PROSKY, L. et al. Determination of insoluble, soluble, and total dietary fiber in foods and food products: interlaboratory study. Journal of the Association of Official Analytical Chemists, Arlington, v.71, n.5, p.1017-1023, 1988.

RIBEIRO, K.M. Efeito da composição nas isotermas de sorção e características do biscoito de polvilho. 2006. 177f. Dissertação (Mestrado em Ciências dos Alimentos) Departamento de Ciências dos Alimentos, Universidade Federal de Lavras, MG.
RIVERA, H.H.P. Fermentação de amido de mandioca (Manihot esculenta Crantz): avaliação e caracterização do polvilho azedo. 1997. 131f. Tese (Doutorado em Ciência e Tecnologia de Alimentos) - Departamento de Tecnologia de Alimentos, Universidade Federal de Viçosa, MG.

SILVA, M.R. et al. Utilização da farinha de jatobá (Hymenaea stigonocarpa Mart.) na elaboração de biscoitos tipo cookie e avaliação de aceitação por testes sensoriais afetivos univariados e multivariados. Ciência e Tecnologia de Alimentos, Campinas, v.18, n.1, p.25-39, 1998. Disponível em: <http:// www.scielo.br/scielo.php? script=sci_arttext $\&$ pid $=$ S0 101 $20611998000100007 \& \operatorname{lng}=$ pt $\& \mathrm{nrm}=\mathrm{iso}>$. Acesso em: 12 jan. 2010. doi: 10.1590/S0101-20611998000100007.

SILVA, C.E.M. et al. Efeito do teor de água, amilose, amilopectina e grau de gelatinização no crescimento do biscoito de amido de mandioca obtido por fermentação natural. Ciência e Tecnologia de Alimentos, Campinas, v.18, n.1, p.60-62, 1998. Disponível em: $<$ http://www.scielo.br/scielo.php?script=sci_arttext\&pid=S0101$20611998000100013 \& \operatorname{lng}=$ pt\&nrm=iso $>$. Acesso em: 12 jan. 2010. doi: 10.1590/S0101-20611998000100013.

STONE, H.; SIDEL, J.L. Sensory evaluation practices. 3.ed. San Diego: Elsevier, 2004. 377p.

WHITNEY, E.; ROLFES, S.R. Nutrição volume 1 - Entendendo os nutrientes. São Paulo: Cengage Learning, 2008. 342p. 